\title{
Origin of craniopharyngiomas: implications for growth pattern, clinical characteristics, and outcomes of tumor recurrence
}

\author{
*Yun Bao, MD, PhD, Jun Pan, MD, PhD, Song-tao Qi, MD, PhD, Yun-tao Lu, MD, PhD, and \\ Jun-xiang Peng, MD, PhD \\ Department of Neurosurgery, Nanfang Hospital, Southern Medical University, Guangzhou, Guangdong, People's Republic of
China
}

OBJECTIVE Craniopharyngiomas are associated with a high rate of recurrence. The surgical management of recurrent lesions has been among the most challenging neurosurgical procedures because of the craniopharyngioma's complex topographical relationship with surrounding structures. The aim of this study was to define the determinative role of the site of origin on the growth pattern and clinical features of recurrent craniopharyngiomas.

METHODS The authors performed a retrospective analysis of 52 patients who had undergone uniform treatment by a single surgeon. For each patient, data concerning symptoms and signs, imaging features, hypothalamic-pituitary function, and recurrence-free survival rate were collected.

RESULTS For children, delayed puberty was more frequent in the group with Type I (infradiaphragmatic) craniopharyngioma than in the group with Type TS (tuberoinfundibular and suprasellar extraventricular) lesions $(p<0.05)$. For adults, blindness was more frequent in the Type I group than in the Type TS group $(p<0.05)$. Nausea or vomiting, delayed puberty, and growth retardation were more frequent in children than in adults $(p<0.05)$. Overall clinical outcome was good in $48.07 \%$ of the patients and poor in $51.92 \%$. Patients with Type TS recurrent tumors had significantly worse functional outcomes and hypothalamic function than patients with the Type I recurrent tumors but better pituitary function especially in children.

CONCLUSIONS The origin of recurrent craniopharyngiomas significantly affected the symptoms, signs, functional outcomes, and hypothalamic-pituitary functions of patients undergoing repeated surgery. Differences in tumor growth patterns and site of origin should be considered when one is comparing outcomes and survival across treatment paradigms in patients with recurrent craniopharyngiomas.

http://thejns.org/doi/abs/10.3171/2015.6.JNS141883

KEY WORDS craniopharyngiomas; recurrence; growth pattern; outcome; oncology

\footnotetext{
$C_{1}$
}

RANIOPHARYNGIOMA, representing $1.2 \%-4.4 \%$ of CNS tumors, can still be challenging. Although its high rate of recurrence. ${ }^{22}$ Recurrent craniopharyngiomas are associated with high morbidity because of the tumor's proximity to vital structures, including the pituitary stalk, hypothalamus, optic apparatus, and vessels in the circle of Willis.
Various strategies have been advocated to improve patient outcomes. Total resection of recurrent craniopharyngioma remains a challenge even in experienced hands, particularly if the lesion involves the hypothalamus and the third ventricle, because of the associated risk of hypothalamic injury. ${ }^{20}$ Loss of arachnoid interposed between the craniopharyngioma and the surrounding hypothalamus has been proposed as a main reason for the higher

ABBREVIATIONS ACTH = adrenocorticotropic hormone; $\mathrm{BMI}=$ body mass index; $\mathrm{DI}=$ diabetes insipidus; $\mathrm{FSH}$ = follicle-stimulating hormone; $\mathrm{GH}=$ growth hormone; $\mathrm{KPS}$

= Karnofsky Performance Scale; $\mathrm{LH}=$ luteinizing hormone; TSH = thyroid-stimulating hormone.

SUBMITTED August 18, 2014. ACCEPTED June 3, 2015.

INCLUDE WHEN CITING Published online December 11, 2015; DOI: 10.3171/2015.6.JNS141883.

* Drs. Bao and Pan contributed equally to this work. 
morbidity associated with surgery for recurrent lesions. ${ }^{7}$ Despite this, many studies have stressed the possibility of the safe resection of recurrent tumors and consider surgery to be the first therapeutic option in such cases. ${ }^{5,18,27,29}$ The role of the site of origin has rarely been studied. The diverse originating points of these tumors lead to variable and complicated growth patterns, a fact that poses significant difficulty in establishing an effective management protocol.

In this study, presurgical symptoms and postsurgical hypothalamic-pituitary function were retrospectively analyzed in 52 patients with recurrent craniopharyngiomas. We examined the clinical associations between infradiaphragmatic and superdiaphragmatic recurrent craniopharyngiomas, as well as the long-term outcomes of patients with these lesions.

\section{Methods}

\section{Standard Protocol Approval, Registration, and Patient Consent}

The study was approved by the medical ethics committee of Nanfang Hospital, Southern Medical University. The medical ethics committee approved a waiver of consent for collection of these data as part of routine clinical care and quality control.

\section{Patient Details}

In the period from January 1997 to January 2009 in our department, 52 patients with recurrent craniopharyngiomas underwent surgery performed by the senior author (S.T.Q.). Eighteen patients had recurrences after primary surgery performed in our department. Thirty-four patients had undergone primary surgery elsewhere. In all patients, the diagnosis of craniopharyngioma was confirmed on histology.

There were 31 male and 21 female patients ranging in age from 4 to 66 years old. The ratio of males to females was 1.47:1. There were 20 children and 32 adults, and 6 of the children had grown into adults when the tumor recurrence was detected. The average age of patients with recurrent craniopharyngioma was $25.51 \pm 2.25$ years.

Calcifications and hydrocephalus accompanied $76.9 \%$ and $53.8 \%$ of the tumor cases, respectively, at the time of the recurrence. Pathological classifications of the recurrent craniopharyngiomas were papillary squamous in 7 patients, adamantinomatous in 43 patients, and mixed type in 2 patients.

\section{Neuroimaging}

We categorized recurrent tumors into 2 types: Type I and Type TS. Type I recurrent tumors originate from below the diaphragm and are therefore infradiaphragmatic (Figs. 1B and 2A and B). These tumors are encased by dura mater and suprasellar arachnoid. Suprasellar extension commonly occurs, but the tumors tend to elevate the diaphragm. Type TS tumors have a supradiaphragmatic origin and are a combination of 2 tumor types, Type $\mathrm{T}$ and Type $\mathrm{S}$. These 2 types are distinguished from each other in primary craniopharyngiomas but not in recurrent tumors (Fig. 1A). Type T tumors originate from the tuberoinfundibulum and involve the third ventricle roof and hypothalamus (Figs. 1D and 2E and F). Pia mater and the diencephalic membrane of Liliequist form the basal part of these tumors. Type $\mathrm{S}$ craniopharyngiomas originate from the proximal segment of the pituitary stalk and are suprasellar extraventricular tumors (Figs. $1 \mathrm{C}$ and $2 \mathrm{C}$ and D). As Type S tumors grow, the third ventricle floor and diaphragma sellae are pushed upward, but the tumor will not involve the third ventricle. These tumors can be subdivided into pre-stalk and retro-stalk craniopharyngiomas.

There were 15 recurrent Type I tumors ( 8 of the 15 patients with Type I tumors were children) and 37 recurrent type TS tumors (12 of the 37 patients with Type I tumors
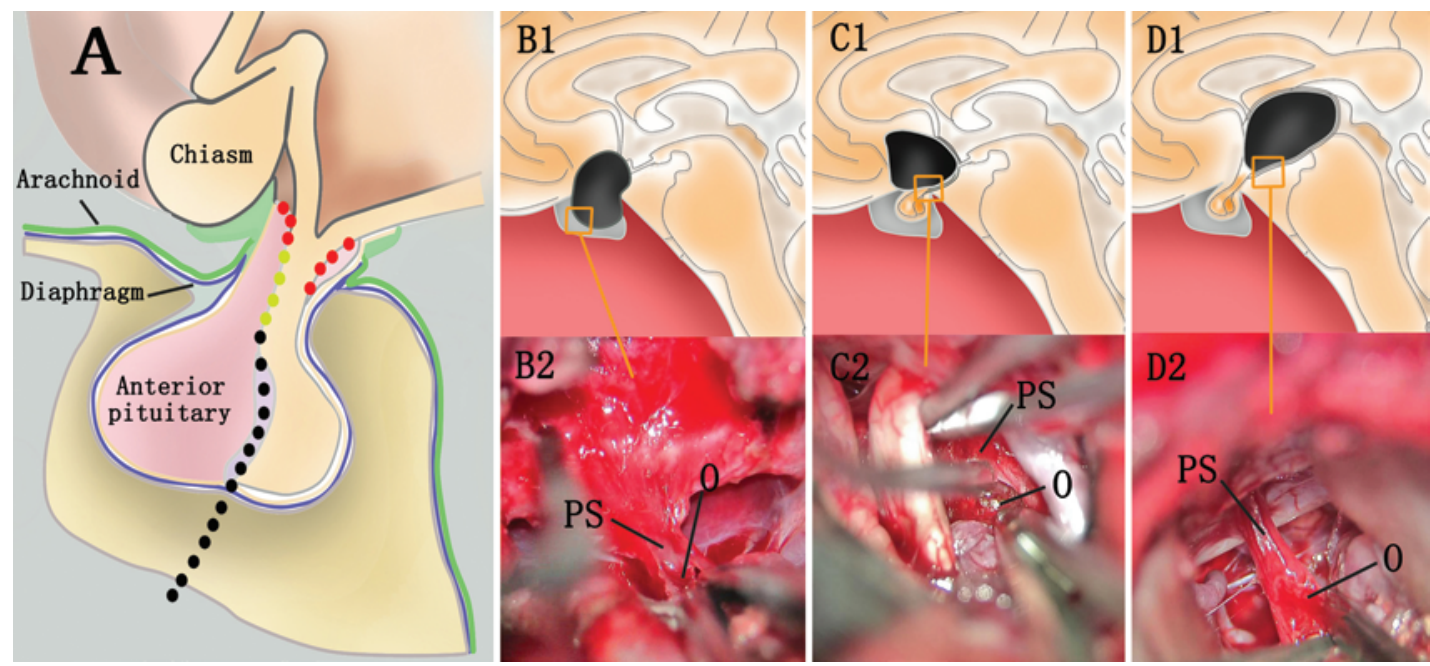

FIG. 1. Different growth patterns of craniopharyngioma. A: Several possible sites of tumor origin are indicated as Type I (black dots), Type S (yellow dots), and Type T (red dots). B: Type I tumors originate from below the diaphragm and are therefore infradiaphragmatic. C: Type S tumors originate from the proximal segment of the pituitary stalk. D: Type T tumors originate from the tuberoinfundibulum. $\mathrm{O}=$ originating point; $\mathrm{PS}=$ pituitary stalk. Copyright Bao Yun. Published with permission. Figure is available in color online only. 


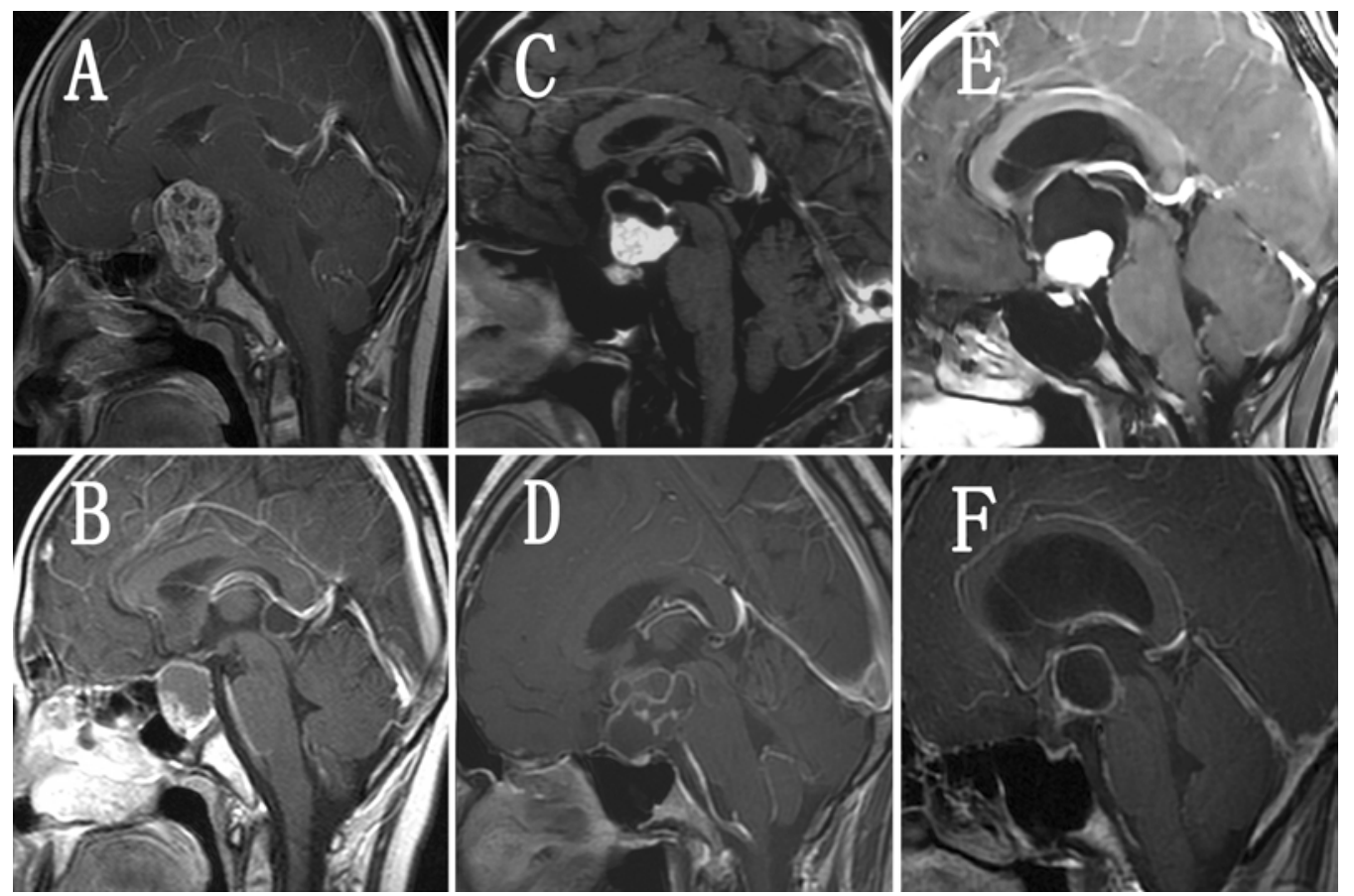

FIG. 2. Preoperative contrast-enhanced MR images show different growth patterns of craniopharyngioma. A: Type I primary craniopharyngioma. B: Type I recurrent craniopharyngioma. C: Type S primary craniopharyngioma. D: Type TS recurrent craniopharyngioma. E: Type T primary craniopharyngioma. F: Type TS recurrent craniopharyngioma. Images in A and B were obtained in the same patient, $C$ and $D$ in the same patient, and $E$ and $F$ in the same patient.

were children). One recurrent tumor was purely intrasellar. In only 1 patient, the topography of the recurrent tumor differed from the primary tumor; that is, the Type I primary lesion changed into a Type TS craniopharyngioma at recurrence. The mean tumor size, defined as the maximal diameter in the midsagittal plane on MRI, was $3.13 \pm 0.21 \mathrm{~cm}$.

\section{Endocrinological Status}

Presurgical and postsurgical pituitary function was evaluated. Adrenocorticotropic hormone (ACTH) deficiency was defined by a peak cortisol value $<500 \mathrm{nmol} / \mathrm{L}$ after provocation testing (insulin hypoglycemia test, glucagon test, or short synacthen test) or $<100 \mathrm{nmol} / \mathrm{L}$ in basal blood samples. Growth hormone (GH) deficiency was defined by a peak value $<10 \mathrm{ng} / \mathrm{ml}$ after effective stimulation in an insulin stimulation test or was diagnosed if the patient had delayed growth and development and short stature (height $>3$ SDs below the mean for the patient's age and sex). Thyroid-stimulating hormone (TSH) deficiency was diagnosed on the basis of low or "inappropriately normal" TSH, with thyroid hormone levels below normal reference values. Gonadotropin deficiency was diagnosed based on follicle-stimulating hormone (FSH) and luteinizing hormone (LH) levels, combined with serum testosterone below the reference values in adult men and with low serum estradiol and oligo-/amenorrhea in adult women. Adolescent patients (girls aged $>12$ years, boys aged $>15$ years) also underwent evaluation for the development of the secondary sex characteristics. Patients were diagnosed as having diabetes insipidus (DI) if urine osmolality was less than $300 \mathrm{mOsm} / \mathrm{kg}$ and urine volume was greater than $3 \mathrm{~L} / 24$ hours.

\section{Treatment}

All 52 patients underwent surgical treatment. The goal of surgery is to remove as much of the tumor as possible without incurring neurological and neuropsychological complications. Resectability following surgery was confirmed by operative findings and postoperative MRI studies read by radiologists. Radical resection of recurrent tumor was achieved in $44(84.60 \%)$ of 52 surgeries. Re-recurrences appeared in $9(17.30 \%)$ of 52 patients who underwent surgery for their first recurrence, that is, in $5(25.0 \%)$ of 20 children within 12-56 months and in 4 $(12.5 \%)$ of 32 adults within 9-38 months. In 1 adult, the tumor recurred for a third time. In 1 child, the tumor recurred for a fifth time. In all patients, radiotherapy was not the first-choice treatment and was performed only as substitute therapy. Eleven patients required a shunting procedure for accompanying hydrocephalus.

\section{Follow-Up}

Outcome was determined using the system outlined by Duff et al.: ${ }^{3}$ good (still alive, no major motor deficit related to treatment or tumor progression, functional vision, Katz grade of $\mathrm{A},{ }^{14}$ Karnofsky Performance Scale [KPS] score of at least 80 , school status of no more than 1 year behind the expected grade for children and young adults, employability for adults of working age, the absence of debilitating psychological or emotional problems); or poor (all patients not meeting the "good" criteria). 
Long-term follow-up data included overall survival rate, recurrence-free survival rate, MRI studies, pituitary function, presence of DI, BMI, and presence of other hypothalamic disturbances. For children, a BMI $>95$ th percentile was considered obesity. For adults, a BMI $>30$ was considered obesity. Cognitive impairment was defined as short-term memory loss, concentration disturbance, behavioral disorders, and disorientation. The Mini-Mental State Examination, Wechsler Memory Scales, Chinese Wechsler Intelligence Scale for Children, and Wechsler Adult Intelligence Scale-Revised in China were performed in this study. Cognitive function was assessed shortly before the operation and during the long-term follow-up period.

Ophthalmological evaluations of visual acuity testing and perimetry were conducted in older children and adults. In the case of young children, appropriate clinical tests were used for visual evaluation. Patients were examined preoperatively; at 1-2 weeks, 3 months, and 6 months after surgery; and at 6-month intervals thereafter. The latest visual status of the patients was graded as follows: either no disturbance or mild impairment, or moderate or severe impairment.

\section{Statistical Analysis}

The chi-square test was used to compare functional outcomes between different groups. Survival and recurrence-free curves were generated using the Kaplan-Meier method, and differences between recurrence-free survival curves were evaluated using the log-rank test. The chisquare test or Fisher exact test was used to compare frequencies of symptoms between different groups. $\mathrm{McNe}-$ mar's test was used to determine whether there was a significant change in hypothalamic-pituitary function and visual function from before to after repeated surgery. Binary logistic regression analysis was performed to explore possible determinants of functional outcome. Data analysis was conducted using SPSS 13.0 (SPSS Inc.). The value for significance was set at $\mathrm{p}<0.05$.

\section{Results}

\section{Symptoms and Signs}

Age, tumor growth pattern, and main symptoms in patients with recurrent craniopharyngiomas are summarized in Table 1 . The most common symptoms were reduced visual field (71.2\%), reduced vision $(69.2 \%)$, and headache $(40.4 \%)$, followed by weight gain (34.6\%), nausea or vomiting (32.7\%), fatigue (32.7\%), polyuria (30.8\%), and memory impairment (21.2\%). For children, delayed puberty was more frequent in the Type I group than in the Type TS group $(\mathrm{p}<0.05)$. For adults, blindness was

TABLE 1. Presenting symptoms in craniopharyngioma, stratified according to age group and growth pattern types*

\begin{tabular}{|c|c|c|c|c|c|c|c|c|}
\hline \multirow[b]{2}{*}{ Symptom } & \multicolumn{3}{|c|}{ Children $(n=20)$} & \multicolumn{3}{|c|}{ Adults $(n=32)$} & \multirow[b]{2}{*}{ Total } & \multirow[b]{2}{*}{ p Value } \\
\hline & Type I (n= 8) & Type TS ( $n=12)$ & $\mathrm{p}$ Value & Type I $(n=7)$ & Type TS $(n=25)$ & $\mathrm{p}$ Value & & \\
\hline Headache & $2(25.0)$ & $3(25.0)$ & 1.000 & $2(28.6)$ & $14(56.0)$ & 0.394 & $21(40.4)$ & 0.074 \\
\hline Nausea or vomiting & $2(25.0)$ & $8(66.7)$ & 0.170 & $1(14.3)$ & $6(24.0)$ & 1.000 & $17(32.7)$ & $0.035 \ddagger$ \\
\hline Diplopia & $0(0.0)$ & $3(25.0)$ & 0.242 & $1(14.3)$ & $1(4.0)$ & 0.395 & $5(9.6)$ & 0.361 \\
\hline Reduced vision & $5(62.5)$ & $6(50.0)$ & 0.670 & $6(85.7)$ & $19(76.0)$ & 1.000 & $36(69.2)$ & 0.079 \\
\hline Reduced visual field & $5(62.5)$ & $7(58.3)$ & 1.000 & $5(71.4)$ & $20(80.0)$ & 0.632 & $37(71.2)$ & 0.160 \\
\hline Blindness & $3(37.5)$ & $1(8.3)$ & 0.255 & $4(57.1)$ & $1(4.0)$ & $0.004 \ddagger$ & $9(17.3)$ & 0.719 \\
\hline Seizures & $3(37.5)$ & $1(8.3)$ & 0.255 & $0(0.0)$ & $3(12.0)$ & 1.000 & $7(13.5)$ & 0.408 \\
\hline Fatigue & $2(25.0)$ & $4(33.3)$ & 1.000 & $1(14.3)$ & $10(40.0)$ & 0.374 & $17(32.7)$ & 0.744 \\
\hline Loss of appetite & $1(12.5)$ & $2(16.7)$ & 1.000 & $0(0.0)$ & $5(20.0)$ & 0.560 & $8(15.4)$ & 1.000 \\
\hline Weight loss & $3(37.5)$ & $1(8.3)$ & 0.255 & $0(0.0)$ & $1(4.0)$ & 1.000 & $5(9.6)$ & 0.066 \\
\hline Polyuria & $2(25.0)$ & $5(41.7)$ & 0.642 & $1(14.3)$ & $8(32.0)$ & 0.640 & $16(30.8)$ & 0.601 \\
\hline Delayed puberty & $7(87.5)$ & $3(25.0)$ & $0.020 \ddagger$ & $2(28.6)$ & $3(12.0)$ & 0.296 & $15(28.8)$ & $0.008 \ddagger$ \\
\hline Growth retardation & $6(75.0)$ & $3(25.0)$ & 0.065 & $1(14.3)$ & $3(12.0)$ & 1.000 & $13(25.0)$ & $0.008 \ddagger$ \\
\hline Increased appetite & $1(12.5)$ & $5(41.7)$ & 0.325 & $2(28.6)$ & $3(12.0)$ & 0.296 & $11(21.2)$ & 0.299 \\
\hline Weight gain & $3(37.5)$ & $6(50.0)$ & 0.670 & $2(28.6)$ & $7(28.0)$ & 1.000 & $18(34.6)$ & 0.213 \\
\hline Insomnia & $0(0.0)$ & $0(0.0)$ & - & $0(0.0)$ & $4(16.0)$ & 0.552 & $4(7.7)$ & 0.151 \\
\hline Depression & $1(12.5)$ & $2(16.7)$ & 1.000 & $0(0.0)$ & $4(16.0)$ & 0.552 & $7(13.5)$ & 1.000 \\
\hline Altered personality & $1(12.5)$ & $0(0.0)$ & 0.400 & $0(0.0)$ & $3(12.0)$ & 1.000 & $4(7.7)$ & 1.000 \\
\hline Memory impairment & $0(0.0)$ & $3(25.0)$ & 0.242 & $0(0.0)$ & $8(32.0)$ & 0.150 & $11(21.2)$ & 0.497 \\
\hline Concentration impairment & $1(12.5)$ & $3(25.0)$ & 0.619 & $0(0.0)$ & $1(4.0)$ & 1.000 & $5(9.6)$ & 0.066 \\
\hline Fever & $0(0.0)$ & $1(8.3)$ & 0.642 & $1(14.3)$ & $0(0.0)$ & 0.219 & $2(3.8)$ & 1.000 \\
\hline Reduced consciousness & $1(12.5)$ & $3(25.0)$ & 1.000 & $0(0.0)$ & $5(20.0)$ & 0.560 & $9(17.3)$ & 0.719 \\
\hline
\end{tabular}

* The chi-square test or Fisher exact test was used to calculate $p$ values. When 0 was observed or the minimal expected frequency was $<1$ in any of the cells across the table, the Fisher exact test was used to compare the difference between groups.

$\dagger$ Values reported for comparative analyses between children and adults.

$\ddagger$ Statistically significant. 
more frequent in the Type I group than in the TS group (p $<0.05$ ). Nausea or vomiting, delayed puberty, and growth retardation were more frequent in children than adults $(\mathrm{p}$ $<0.05)$. The difference in number between Type I and Type TS tumors in children and adults was not great $(8$ children and 7 adults in the Type I group; 12 children and 25 adults in the Type TS group).

The mean KPS score at the last follow-up was 57.88. Final functional outcomes are shown in Fig. 3. The overall clinical outcome was good in $48.07 \%$ of the patients and poor in $51.92 \%$. Patients with Type I recurrent craniopharyngiomas had a better outcome than those with the Type TS craniopharyngiomas $(\mathrm{p}<0.05)$. Logistic regression analysis (Table 2) showed that growth pattern and hydrocephalus were independent covariates that significantly affected outcomes after repeated surgery. Age at surgery, sex, tumor size, histological type, and calcification did not significantly affect outcomes.

\section{Recurrence-Free Survival Rates}

Nine of the 52 patients died during the follow-up period. Perioperative death occurred in $2(3.85 \%)$ of the cases. One patient died of a heart attack 3 years after surgery. Six deaths were related to the impairment of hypothalamic-pituitary function. All deaths related to craniopharyngiomas occurred within the first 5 years after repeated surgery.

Surviving patients were followed up for at least 5 years after repeat surgery. The mean follow-up among 52 patients after surgery was 74.57 months. Recurrence-free survival rates for all of the patients since presentation are shown in Fig. 4. There was no significant difference in the recurrence-free survival rates at various time points between Type I and Type TS craniopharyngioma.

\section{Hypothalamic-Pituitary Function and Visual Function}

The cumulative probability for each deficit in all patients is shown in Table 3. Of 52 patients, 14 had preoperative panhypopituitarism. Of the remaining 38 patients, new anterior hypopituitarism occurred in 7 patients (18.4\%) with at least 1 intact axis preoperatively (including new $\mathrm{ACTH}, \mathrm{TSH}, \mathrm{GH}$, and $\mathrm{LH} / \mathrm{FSH}$ loss in $0 \%, 15.7 \%$, $2.6 \%$, and $2.6 \%$, respectively). Hormonal status was not significantly changed in any of the patients after reoperation except for TSH deficiency. The ACTH deficiency rate postoperation $(48.1 \%)$ was lower than that preoperation
TABLE 2. Logistic regression analysis of predictors of outcome

\begin{tabular}{lrl}
\hline \multicolumn{1}{c}{ Variable } & B & p Value \\
\hline Age at op & 1.813 & 0.124 \\
\hline Sex & -2.304 & 0.102 \\
\hline Lesion size & 0.289 & 0.425 \\
\hline Extent of resection & 22.844 & 0.998 \\
\hline Growth pattern & 5.102 & $0.007^{*}$ \\
\hline Hydrocephalus & 2.962 & $0.019^{*}$ \\
\hline Histopathological type & 1.093 & 0.364 \\
\hline Calcification & 1.270 & 0.293 \\
\hline
\end{tabular}

* Statistically significant.

(53.8\%). The ACTH and LH/FSH deficiencies presented more frequently in children with Type I craniopharyngioma $(\mathrm{p}<0.05)$. Growth hormone deficiency presented more frequently in adults than in children $(\mathrm{p}<0.05)$.

Nine (3 with Type I and 6 with Type TS lesions) of the 20 children and 9 ( 2 with Type I and 7 with Type TS) of the 32 adults were obese before repeated surgery. Of the remaining 34 patients, resection of recurrent tumors led to new obesity in 3 children (27.2\%) and 2 adults (86.9\%). Three new instances of cognitive impairment appeared after surgery for a recurrence. Mild recent memory disturbances occurred in 1 patient, and mood instability occurred in another 2 patients. Cognitive impairment and obesity were significantly higher in the Type TS group than in the Type I group $(\mathrm{p}<0.05)$.

Visual function remained stable after reoperations except in 5 patients. After repeat surgery, visual function improved in 3 patients and worsened in 2 of the 52 patients. There was no significant difference in visual function between the different lesion type groups and age groups ( $\mathrm{p}$ $>0.05$ ).

\section{Surgical Approach}

Although 1 patient with a purely intrasellar recurrent Type I tumor underwent a transsphenoidal approach, the remaining patients underwent either a pterional or translamina terminalis approach (Table 4). Type TS tumors were treated using a variety of approaches including the pterional, translamina terminalis, subfrontal, and transventricular approaches.
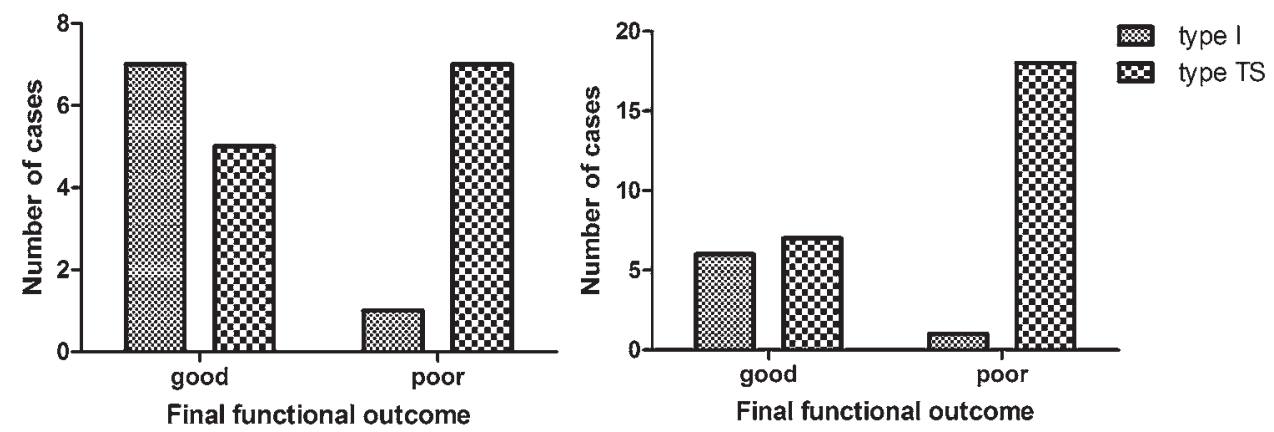

FIG. 3. Functional outcomes in the 52 cases of recurrent craniopharyngioma. Left: Functional outcome in children. Right: Functional outcome in adults. 

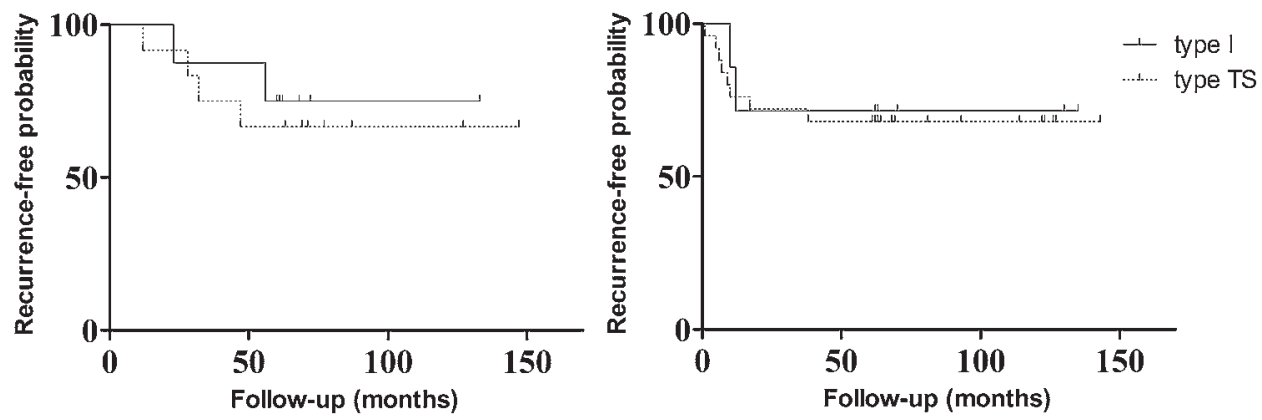

FIG. 4. Recurrence-free survival curves in 52 patients with recurrent craniopharyngiomas. Left: Recurrence-free survival curves for children. Right: Recurrence-free survival curves for adults.

\section{Discussion}

\section{Growth Pattern of Recurrent Craniopharyngiomas}

In our previous paper, an arachnoidal sleeve was found enveloping the pituitary stalk. Accordingly, craniopharyngiomas originating along the developing path of the stalk can manifest different topographic relations with these membrane structures. ${ }^{21}$ Taking into consideration presurgical MRI studies, intraoperative findings, and the original lesion site, we classified tumors into 3 subtypes: Type I, Type S, and Type T. This surgical classification scheme highlights the original tumor site and the relationship between tumor and the suprasellar membrane structures. A profound understanding of each tumor's growth pattern and the arachnoidea around the pituitary is very important. For subdiaphragmatic tumors, the recurrence would originate from intrasellar structures as these are the probable sites of adhesion. ${ }^{4,716}$ In only 1 patient in the present study, the growth pattern of the recurrent tumor differed from the primary tumor. Tumors that were originally infradiaphragmatic grew secondarily suprasellar, which might have been related to residual tumor in the pituitary stalk. These data suggested that the originating point of the primary tumor has a direct effect on the growth pattern of recurrent craniopharyngiomas. Most of the recurrent craniopharyngiomas had the same site of origin and growth patterns as the primary tumor, although these lesions can recur at a distant site. . $^{1,6,8,9,17}$

\section{Symptoms and Signs}

Delayed puberty was significantly more frequent in children with Type I than Type TS craniopharyngioma. For children with the Type I tumor, the GH replacement therapy might be emphasized. Blindness was significantly more frequent in adults with the Type I tumor than those with the Type TS tumors. All instances of new blindness appeared before repeated surgery. These data suggest that the optic nerve may be easily affected by tumors after the first surgery or radiotherapy. However, obesity was more frequent in children with Type TS than with Type I tumors because of the specific relationship between Type TS tumors and the hypothalamus. Among adult craniopharyngiomas, there were no significant differences in delayed puberty, growth retardation, or obesity between the 2 different lesion growth patterns. The point of tumor origin may play a more important role in children. In the current study, nausea or vomiting, delayed puberty, growth retardation, and concentration impairment were more frequent among children than adults before repeated surgery. In contrast to this finding, Karavitaki et al. ${ }^{15}$ found no difference in the duration of most clinical manifestations between child- and adult-onset disease.

\section{Hypothalamic-Pituitary Functions}

Previous studies on craniopharyngiomas have indicated that the recovery of an endocrinological defect is very rare. ${ }^{12,19} \mathrm{We}$ found some restorations of an ACTH deficit after surgical intervention in the patients with recurrent craniopharyngiomas. This finding suggests that some damage to the hypothalamic-pituitary system exerted by the hydrocephalus (when present) or the tumor itself is not permanent. In many cases of craniopharyngiomas, a newly developed postoperative endocrinological abnormality is expected after tumor resection. ${ }^{7,26}$ In previous reports the deterioration of endocrinological function may be attributed to surgical interventions (primary or for recurrences) or the effects of radiotherapy, as well as damage by the tumor. ${ }^{15}$ In our series, new anterior hypopituitarism occurred in 7 patients (18.4\%) with at least 1 intact axis preoperatively (including new ACTH, TSH, GH, and LH/FSH loss in $0 \%, 15.7 \%, 2.6 \%$, and $2.6 \%$, respectively). Repeat operations were better tolerated than the first surgery in terms of pituitary function because endocrine disturbances were already established and balanced by medical treatments. ${ }^{13,26}$ Only the postoperative TSH deficiency rate was higher than its preoperative rate. Therefore, in some cases, thyroid hormone replacement therapy may be required to manage hypothyroidism after surgery.

Hypothalamic-pituitary dysfunction in recurrent craniopharyngiomas may be largely related to tumor location. For children, postoperative hypopituitarism was more common in those with Type I craniopharyngiomas than those with Type TS tumors. Varying degrees of hypopituitarism may be attributable to the different compressive injuries to the pituitary gland. In the present study, postoperative obesity was more frequent among children with recurrent Type TS craniopharyngiomas than those with Type I tumors. A similar result was demonstrated in the study by De Vile et al. ${ }^{2}$ In our study, GH deficiency presented more frequently in adults than in children both preand postoperatively, but GH replacement therapy should not be neglected. There was no significant difference in 


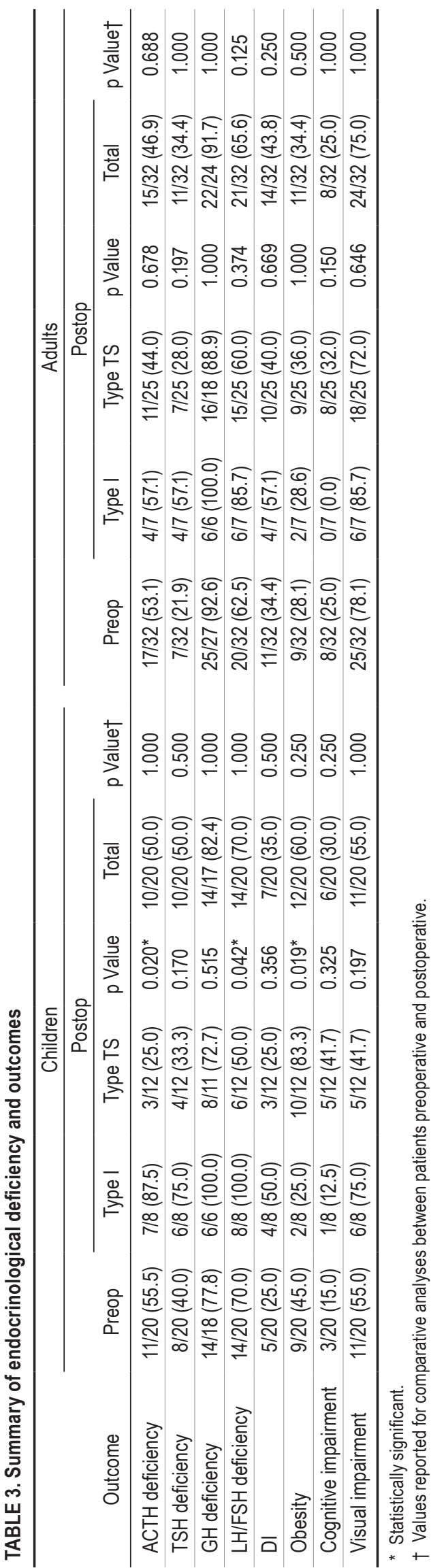

TABLE 4. Surgical approaches to recurrent craniopharyngiomas

\begin{tabular}{|c|c|c|c|}
\hline Variable & $\begin{array}{l}\text { Initial/Previous } \\
\text { Approach }\end{array}$ & Repeat Approach & $\begin{array}{r}\text { No. } 0 \\
\text { Ops }\end{array}$ \\
\hline \multicolumn{4}{|c|}{ Lesion Group } \\
\hline \multirow[t]{6}{*}{ Type I } & Pterional & Pterional & 7 \\
\hline & Pterional & $\begin{array}{l}\text { Frontal base interhemi- } \\
\text { spheric }\end{array}$ & 4 \\
\hline & Pterional & Transsphenoidal & 1 \\
\hline & Transcallosal & $\begin{array}{l}\text { Frontal base interhemi- } \\
\text { spheric }\end{array}$ & 1 \\
\hline & Transsphenoidal & Pterional & 1 \\
\hline & Transsphenoidal & $\begin{array}{l}\text { Frontal base interhemi- } \\
\text { spheric }\end{array}$ & 1 \\
\hline \multirow[t]{9}{*}{ Type TS } & Pterional & Pterional & 18 \\
\hline & Pterional & $\begin{array}{l}\text { Frontal base interhemi- } \\
\text { spheric }\end{array}$ & 9 \\
\hline & Pterional & Subfrontal & 1 \\
\hline & Transcallosal & Pterional & 2 \\
\hline & Transcallosal & $\begin{array}{l}\text { Frontal base interhemi- } \\
\text { spheric }\end{array}$ & 2 \\
\hline & $\begin{array}{l}\text { Translamina ter- } \\
\text { minalis }\end{array}$ & $\begin{array}{l}\text { Frontal base interhemi- } \\
\text { spheric }\end{array}$ & 2 \\
\hline & Lateral ventricle & Lateral ventricle & 1 \\
\hline & Lateral ventricle & $\begin{array}{l}\text { Frontal base interhemi- } \\
\text { spheric }\end{array}$ & 1 \\
\hline & Lateral ventricle & Pterional & 1 \\
\hline Total ops & & & 52 \\
\hline
\end{tabular}

postoperative hypopituitarism between Type I and Type TS craniopharyngiomas in adults. The point of origin of a craniopharyngioma may play a more important role in children than in adults.

\section{Recurrence-Free Survival}

Tumor recurrence is a very common event in the management of craniopharyngiomas, even after complete resection and postoperative radiotherapy. It has been reported that most recurrences appear during the first 5 years following treatment. ${ }^{10,23,24,28}$ In the present series, most recurrences appeared during the first 3 years after repeated surgery, indicating that the re-recurrence time was shorter than the first recurrence time.

Eight patients in the present study had a Type S primary craniopharyngioma. One of these patients underwent primary surgery at our hospital, a procedure during which the pituitary stalk and neurohypophysis were morphologically preserved. Residual tumor was found in the area of the pituitary stalk on postoperative imaging. Some factors affected the recurrence rate of Type I and Type TS craniopharyngiomas. Severe hypothalamic involvement leads to conservative surgery in some patients with Type TS craniopharyngiomas. In the operations for some Type I craniopharyngiomas, tumors cannot be directly visualized. After lesion removal, closure of the sellar floor and diaphragma sellae is required. 


\section{Recurrence-Free Survival Rates and Outcomes}

Patients with recurrent craniopharyngiomas have high rates of mortality and morbidity.,11,25,27 Multiple recurrences and the subsequent therapeutic interventions can also contribute to increased mortality. We did not find a difference in overall mortality rates and recurrence-free survival rates between the 2 tumor growth pattern groups. However, our data suggest that growth pattern is the independent covariate that significantly affected outcomes after repeated surgery. Patients with Type I recurrent craniopharyngioma had a significantly better long-term outcome than those with a Type TS tumor. In Type TS tumors, adhesion between the tumor and adjacent structures tended to be more prominent in the absence of an intervening diaphragma sellae. This extensive adhesion may result in frequent postoperative complications and a worse long-term outcome.

\section{Study Limitations}

The major limitations of this study are the biases resulting from the retrospective manner of data collection, the limited number of patients, missing hormonal data, and the lack of detailed pre- and postoperative neuropsychological testing in 2 children. Given that most of the postoperative hormonal testing was completed at outside facilities, missing data were unavoidable in some patients. All patients had complete pre- and postoperative data for adrenal, thyroid, gonadal, and posterior pituitary function status, and $75 \%$ of the patients had sufficient data to assess for GH deficiency. Furthermore, the retrospective nature of the analysis impedes evaluation of the management of recurrence because the choice of treatment reflects the location of the tumor. The study's strengths lie in the lengthy follow-up and uniform treatment paradigm in all patients.

\section{Conclusions}

The site of recurrent tumor origin has a direct effect on the growth pattern of recurrent craniopharyngiomas, which may serve as a useful index for anticipating clinical features, functional outcome, and surgical management. Additional hypothalamic-pituitary dysfunction does not occur frequently following surgical treatment. The site of recurrent tumor origin significantly influenced hypothalamic-pituitary function. Patients with Type I craniopharyngiomas have a better functional outcome and hypothalamic status than those with Type TS tumors but worse pituitary function after repeated surgery. Differences in tumor growth patterns and point of origin should be considered when comparing outcomes and survival across treatment paradigms in patients with recurrent craniopharyngiomas.

\section{Acknowledgments}

This research was funded by the GuangDong Province Natural Science Funding (No. S2011010003063, S2012020010939), the Key Clinical Specialty Discipline Construction Program, and President Foundation of Nanfang Hospital, Southern Medical University (2012Z004).

\section{References}

1. Barloon TJ, Yuh WT, Sato Y, Sickels WJ: Frontal lobe im- plantation of craniopharyngioma by repeated needle aspirations. AJNR Am J Neuroradiol 9:406-407, 1988

2. De Vile CJ, Grant DB, Kendall BE, Neville BG, Stanhope R, Watkins KE, et al: Management of childhood craniopharyngioma: can the morbidity of radical surgery be predicted? J Neurosurg 85:73-81, 1996

3. Duff J, Meyer FB, Ilstrup DM, Laws ER Jr, Schleck CD, Scheithauer BW: Long-term outcomes for surgically resected craniopharyngiomas. Neurosurgery 46:291-305, 2000

4. Eldevik OP, Blaivas M, Gabrielsen TO, Hald JK, Chandler WF: Craniopharyngioma: radiologic and histologic findings and recurrence. AJNR Am J Neuroradiol 17:1427-1439, 1996

5. Elliott RE, Hsieh K, Hochm T, Belitskaya-Levy I, Wisoff J, Wisoff JH: Efficacy and safety of radical resection of primary and recurrent craniopharyngiomas in 86 children. J Neurosurg Pediatr 5:30-48, 2010

6. Elmaci L, Kurtkaya-Yapicier O, Ekinci G, Sav A, Pamir MN, Vidal S, et al: Metastatic papillary craniopharyngioma: case study and study of tumor angiogenesis. Neuro Oncol 4:123128,2002

7. Fahlbusch R, Honegger J, Paulus W, Huk W, Buchfelder M: Surgical treatment of craniopharyngiomas: experience with 168 patients. J Neurosurg 90:237-250, 1999

8. Frangou EM, Tynan JR, Robinson CA, Ogieglo LM, Vitali AM: Metastatic craniopharyngioma: case report and literature review. Childs Nerv Syst 25:1143-1147, 2009

9. Gupta K, Kuhn MJ, Shevlin DW, Wacaser LE: Metastatic craniopharyngioma. AJNR Am J Neuroradiol 20:10591060, 1999

10. Hoffman HJ: Surgical management of craniopharyngioma. Pediatr Neurosurg 21 (Suppl 1):44-49, 1994

11. Hoffman HJ, De Silva M, Humphreys RP, Drake JM, Smith ML, Blaser SI: Aggressive surgical management of craniopharyngiomas in children. J Neurosurg 76:47-52, 1992

12. Honegger J, Buchfelder M, Fahlbusch R: Surgical treatment of craniopharyngiomas: endocrinological results. J Neurosurg 90:251-257, 1999

13. Jang WY, Lee KS, Son BC, Jeun SS, Hong YK, Lee SW, et al: Repeat operations in pediatric patients with recurrent craniopharyngiomas. Pediatr Neurosurg 45:451-455, 2009

14. Katz S, Ford AB, Moskowitz RW, Jackson BA, Jaffe MW: Studies of illness in the aged. The Index of ADL: a standardized measure of biological and psychosocial function. JAMA 185:914-919, 1963

15. Karavitaki N, Brufani C, Warner JT, Adams CB, Richards P, Ansorge $\mathrm{O}$, et al: Craniopharyngiomas in children and adults: systematic analysis of 121 cases with long-term follow-up. Clin Endocrinol (Oxf) 62:397-409, 2005

16. Kim SK, Wang KC, Shin SH, Choe G, Chi JG, Cho BK: Radical excision of pediatric craniopharyngioma: recurrence pattern and prognostic factors. Childs Nerv Syst 17:531-537, 2001

17. Malik JM, Cosgrove GR, VandenBerg SR: Remote recurrence of craniopharyngioma in the epidural space. Case report. J Neurosurg 77:804-807, 1992

18. Minamida Y, Mikami T, Hashi K, Houkin K: Surgical management of the recurrence and regrowth of craniopharyngiomas. J Neurosurg 103:224-232, 2005

19. Paja M, Lucas T, García-Uría J, Salamé F, Barceló B, Estrada $\mathrm{J}$ : Hypothalamic-pituitary dysfunction in patients with craniopharyngioma. Clin Endocrinol (Oxf) 42:467-473, 1995

20. Prieto R, Pascual JM, Subhi-Issa I, Jorquera M, Yus M, Martínez R: Predictive factors for craniopharyngioma recurrence: a systematic review and illustrative case report of a rapid recurrence. World Neurosurg 79:733-749, 2013

21. Qi S, Lu Y, Pan J, Zhang X, Long H, Fan J: Anatomic relations of the arachnoidea around the pituitary stalk: relevance 
for surgical removal of craniopharyngiomas. Acta Neurochir (Wien) 153:785-796, 2011

22. Raimondi AJ, Rougerie J: A critical review of personal experiences with craniopharyngioma: clinical history, surgical technique and operative results. 1983. Pediatr Neurosurg 21:134-154, 1994

23. Shapiro K, Till K, Grant DN: Craniopharyngiomas in childhood. A rational approach to treatment. J Neurosurg 50:617-623, 1979

24. Tomita T, McLone DG: Radical resections of childhood craniopharyngiomas. Pediatr Neurosurg 19:6-14, 1993

25. Van Effenterre R, Boch AL: Craniopharyngioma in adults and children: a study of 122 surgical cases. J Neurosurg 97:3-11, 2002

26. Weiner HL, Wisoff JH, Rosenberg ME, Kupersmith MJ, Cohen H, Zagzag D, et al: Craniopharyngiomas: a clinicopathological analysis of factors predictive of recurrence and functional outcome. Neurosurgery 35:1001-1011, 1994

27. Wisoff JH: Surgical management of recurrent craniopharyngiomas. Pediatr Neurosurg 21 (Suppl 1):108-113, 1994

28. Yaşargil MG, Curcic M, Kis M, Siegenthaler G, Teddy PJ, Roth P: Total removal of craniopharyngiomas. Approaches and long-term results in 144 patients. J Neurosurg 73:3-11, 1990
29. Zuccaro G: Radical resection of craniopharyngioma. Childs Nerv Syst 21:679-690, 2005

\section{Disclosures}

The authors report no conflict of interest concerning the materials or methods used in this study or the findings specified in this paper.

\section{Author Contributions}

Conception and design: Qi, Bao. Acquisition of data: Bao, Pan, Peng. Analysis and interpretation of data: Bao, Pan, Lu. Drafting the article: Bao. Critically revising the article: Qi, Bao, Lu, Peng. Reviewed submitted version of manuscript: Qi, Bao, Pan. Approved the final version of the manuscript on behalf of all authors: Qi. Statistical analysis: Bao. Administrative/technical/ material support: all authors. Study supervision: Qi, Pan, Lu.

\section{Correspondence}

Song-tao Qi, Guangzhou Dadao Bei St. \#1838, GuangZhou 510515, P. R. China. email:qisongtaosjwk@163.com. 